\title{
Short communication: Multistate outbreak of Listeria monocytogenes infections retrospectively linked to unpasteurized milk using whole-genome sequencing
}

\author{
Megin Nichols, ${ }^{1 *}$ Amanda Conrad, ${ }^{1}$ Laura Whitlock, ${ }^{1}$ Steven Stroika, ${ }^{1}$ Errol Strain, ${ }^{2}$ Andre Weltman, ${ }^{3}$ \\ Lydia Johnson, ${ }^{4}$ Jamie DeMent, ${ }^{5}$ Roshan Reporter, ${ }^{6}$ and lan Williams ${ }^{1}$ \\ ${ }^{1}$ Centers for Disease Control and Prevention, Atlanta, GA 30329 \\ ${ }^{2}$ Food and Drug Administration, College Park, MD 20740 \\ ${ }^{3}$ Pennsylvania Department of Health, Harrisburg 17120 \\ ${ }^{4}$ Pennsylvania Department of Agriculture, Harrisburg 17120 \\ ${ }^{5}$ Food and Waterborne Disease Program, Florida Department of Health, Tallahassee 32399 \\ ${ }^{6}$ Los Angeles County Department of Public Health, Los Angeles, CA 90007
}

\begin{abstract}
Unpasteurized milk can contain harmful bacteria such as Listeria monocytogenes. In 2016, the US Food and Drug Administration notified the Centers for Disease Control and Prevention (Atlanta, GA) that $L$. monocytogenes isolated from unpasteurized chocolate milk from a Pennsylvania dairy was closely related, by whole-genome sequencing, to L. monocytogenes isolates collected from blood specimens of 2 patients (in California and Florida) in 2014. The California and Florida patients consumed unpasteurized milk from the Pennsylvania dairy. Both were $>65$ yr old and were hospitalized in 2014; the Florida patient died. Isolates from the 2 patients had indistinguishable pulsed-field gel electrophoresis patterns and were closely related by whole-genome multilocus sequence typing analysis (by 2 alleles) to the isolate from unpasteurized chocolate milk produced by the Pennsylvania dairy in 2015 . Together, epidemiologic and laboratory information indicated a common origin. This is the first multistate listeriosis outbreak linked to unpasteurized milk in the United States detected using whole-genome multilocus sequence analysis.
\end{abstract}

Key words: Listeria, outbreak, unpasteurized milk, raw milk

\section{Short Communication}

Listeriosis resulting from the consumption of contaminated foods can pose severe health risks, including death, especially among pregnant women and their newborns, adults aged $65 \mathrm{yr}$ or older, and people with

Received March 28, 2019.

Accepted August 22, 2019.

*Corresponding author: mcnichols@cdc.gov weakened immune systems. Unpasteurized milk and dairy products can contain harmful bacteria such as Listeria, Salmonella, Escherichia coli, and Campylobacter, and parasites such as Cryptosporidium (Oliver et al., 2005; Crim et al., 2015; Mungai et al., 2015). In the United States, a small proportion of Listeria monocytogenes illnesses are linked to recognized outbreaks (Crim et al., 2015; Jackson et al., 2016). Although listeriosis outbreaks linked to soft cheese made from unpasteurized milk were commonly reported from 1998 to 2015 through the Centers for Disease Control and Prevention (CDC) National Outbreak Reporting System (NORS), no listeriosis outbreaks linked to unpasteurized milk were reported (Langer et al., 2012; NORS, 2018).

To facilitate listeriosis outbreak detection, a multiagency effort began in 2013 to perform real-time wholegenome sequencing (WGS) on all L. monocytogenes isolates from patients, food, and the environment (Jackson et al., 2016). To aid in outbreak detection, raw sequencing data are posted to a public repository at the National Center for Biotechnology Information. Data obtained through whole-genome multilocus sequence typing and high-quality (hq)SNP analyses, combined with patient exposure data, aids in the investigation of L. monocytogenes outbreaks and can lead to the detection of potentially contaminated food products (Jackson et al., 2016).

In November 2015, dairy farm X in Pennsylvania transported several unpasteurized dairy products to a conference in Anaheim, California, for distribution to conference attendees. In California, it is unlawful for any person to sell, give away, deliver, or knowingly purchase or receive milk or milk products that do not conform to the standards established in the California Food and Agricultural Code and the California Code of Regulations (California Department of Food and Ag- 
riculture, 2015). This includes milk or milk products produced on a dairy farm that does not hold a permit issued by the California Department of Food and Agriculture or a County Approved Milk Inspection Service (California Department of Food and Agriculture, 2015). Under federal regulations, it is unlawful to ship unpasteurized milk or unpasteurized milk products in interstate commerce for direct human consumption, with a few exceptions, including one for certain standardized cheeses, aged for a minimum of $60 \mathrm{~d}$ at a temperature of $35^{\circ} \mathrm{F}\left(1.67^{\circ} \mathrm{C}\right)$ or above (FDA, 2017). Dairy farm X transported dairy products for distribution to the conference attendees but did not hold a California permit; local officials in Orange County, California, embargoed the unpasteurized dairy products and sent samples for foodborne pathogen testing to the United States Food and Drug Administration (FDA). When L. monocytogenes was isolated from the unpasteurized chocolate milk samples, the FDA performed pulsed-field gel electrophoresis (PFGE) and WGS on the L. monocytogenes isolates. In January 2016, the FDA informed the CDC that hqSNP data analysis had shown that the L. monocytogenes isolates from the unpasteurized chocolate milk [National Center for Biotechnology Information Sequence Read Archive (SRA): SRS1210860, SRS1210888] were closely related genetically by 6 hqSNP to L. monocytogenes isolates collected from blood specimens from 2 patients in 2014: 1 from California (SRA: SRS662452) and 1 from Florida (SRA: SRS811568). Upon notification by the FDA, the CDC initiated an investigation with state public health, state agriculture, and federal health and regulatory partners.

PulseNet, the national laboratory network of public health and food regulatory agency laboratories, coordinated by the CDC, collaborated with partners to determine the degree of genetic relatedness among the L. monocytogenes isolates by examining PFGE patterns and WGS data for the 3 isolates using whole-genome multilocus sequence typing. The CDC, with local or state health authority assent, conducted epidemiologic interviews about unpasteurized milk consumption with the California patient, and through family member surrogates for the Florida patient. The CDC contacted the Pennsylvania Department of Agriculture for information about the origin and production of the unpasteurized dairy products embargoed at the conference in California.

The L. monocytogenes isolates from the 2 ill patients in 2014 had indistinguishable PFGE patterns and were closely related (2 alleles) by whole-genome multilocus sequence typing analysis to the isolate from the unpasteurized chocolate milk produced by dairy farm $\mathrm{X}$ in Pennsylvania. The patients from California and Florida were both aged $>65$ yr and were hospitalized in 2014; the Florida patient died. The extent to which L. monocytogenes infection contributed to the death of the Florida patient is unknown; gastric lymphoma was listed as the cause of death on the death certificate. The family member surrogate interviewed was a member of dairy farm X's buyers' club while the patient lived in the family member's home; the family member ordered products online, which were shipped interstate to Florida. The California patient reported consuming unpasteurized "buttermilk," which was also provided by a family member who purchased unpasteurized milk from dairy farm $\mathrm{X}$ through the same buyers' club as the Florida patient's surrogate.

Unpasteurized milk sales are legal on-farm and in retail stores in Pennsylvania. A permit is required for the sale of milk, milk products, and manufactured dairy products within the state (Pennsylvania Statutes, 1982, 1961). Dairy farm X was not selling milk via a store or on-farm, but through a buyers' club to out-of-state members; therefore, dairy farm $\mathrm{X}$ was not required to have a permit, was not inspected by the Pennsylvania Department of Agriculture, and was unlawfully shipping unpasteurized milk and unpasteurized milk products in interstate commerce (Pennsylvania Statutes, 1982, 1961; FDA, 2017). The CDC posted an outbreak announcement online because of concerns that contaminated unpasteurized milk and other unpasteurized dairy products from dairy farm $\mathrm{X}$ were still being sold across the United States and could result in additional L. monocytogenes illnesses (CDC, 2016). The web announcement recommended that people drink and eat only pasteurized dairy products, including milk, soft cheese, ice cream, and yogurt (CDC, 2016).

The source of the 2 illnesses in 2014 was unknown until WGS analysis of L. monocytogenes isolated from the unpasteurized chocolate milk sample in 2016 determined that the 3 isolates were related and exposure information indicated a common origin. Collaborative investigative efforts by state, local, and federal public health and regulatory officials indicated that unpasteurized milk produced by dairy farm X in Pennsylvania was the likely source of this outbreak. A state authority does not regulate milk production by dairy farm $\mathrm{X}$ because sales are conducted through an online buyers' club in which members order products online and then arrange for shipping via the mail or other mechanisms. Public health officials were unable to obtain a list of dairy farm X buyers' club members.

This is the first multistate listeriosis outbreak linked to unpasteurized milk detected in the United States. Detection of illness outbreaks resulting from enteric pathogens in high-risk food products, such as unpasteurized milk, will likely increase with broadening application of WGS analyses. The greater discriminatory 
power of WGS allows for the identification of isolates from multiple states that might share a common source, and provides more confidence in the epidemiologic associations between isolates from humans and from food products.

Pathogens in unpasteurized milk and dairy products made from unpasteurized milk can pose severe health risks, including death, for people at higher risk for foodborne illness. Producers and vendors of unpasteurized milk and dairy products should always comply with federal and state public health regulations. However, outbreaks of illness can continue to occur despite producers' compliance with regulations, on-farm inspections, improved animal health and husbandry, and cleaning of milking equipment. Mitigation of illnesses and deaths resulting from pathogens in milk has been achieved through pasteurization; therefore, the CDC continues to recommend that people, especially those at high risk for severe illness, drink and eat only pasteurized dairy products.

\section{ACKNOWLEDGMENTS}

The authors acknowledge Hilary E. Rosen and Akiko Kimura from the California Department of Public Health for their assistance during this investigation. We also acknowledge the Orange County Health Care Agency Regulatory/Medical Health Services, Environmental Health Division for their contributions to the investigation. Disclaimer: The findings and conclusions in this report are those of the authors and do not necessarily represent the official position of Centers for Disease Control and Prevention.

\section{REFERENCES}

California Department of Food and Agriculture. 2015. Regulatory requirements for distribution of milk for raw consumption in California. Accessed Mar. 1, 2018. https://www.cdfa.ca.gov/ahfss/Milk
_and_Dairy_Food_Safety/pdfs/RawMilkRequirementsSummary .pdf.

CDC (Centers for Disease Control and Prevention). 2016. Multistate outbreak of listeriosis linked to raw milk produced by Miller's Organic Farm in Pennsylvania. Accessed Mar. 1, 2018. https://www .cdc.gov/listeria/outbreaks/raw-milk-03-16/index.html.

Crim, S. M., P. M. Griffin, R. Tauxe, E. P. Marder, D. Gilliss, A. B. Cronquist, M. Cartter, M. Tobin-D'Angelo, D. Blythe, K. Smith, S. Lathrop, S. Zansky, P. R. Cieslak, J. Dunn, K. G. Holt, B. Wolpert, O. L. Henao, and Centers for Disease Control and Prevention. 2015. Preliminary incidence and trends of infection with pathogens transmitted commonly through food - Foodborne Diseases Active Surveillance Network, 10 U.S. sites, 2006-2014. MMWR Morb. Mortal. Wkly. Rep. 64:495-499.

FDA (Food and Drug Administration). 2017. Code of Federal Regulations Title 21 Food and Drugs. Vol. 8. Accessed Mar. 1, 2018. https://www.accessdata.fda.gov/scripts/cdrh/cfdocs/cfcfr/ CFRSearch.cfm?fr=1240.61.

Jackson, B. R., C. Tarr, E. Strain, K. A. Jackson, A. Conrad, H. Carleton, L. S. Katz, S. Stroika, L. H. Gould, R. K. Mody, B. J. Silk, J. Beal, Y. Chen, R. Timme, M. Doyle, A. Fields, M. Wise, G. Tillman, S. Defibaugh-Chavez, Z. Kucerova, A. Sabol, K. Roache, E. Trees, M. Simmons, J. Wasilenko, K. Kubota, H. Pouseele, W. Klimke, J. Besser, E. Brown, M. Allard, and P. Gerner-Smidt. 2016. Implementation of nationwide real-time whole-genome sequencing to enhance listeriosis outbreak detection and investigation. Clin. Infect. Dis. 63:380-386. https://doi.org/10.1093/cid/ ciw242.

Langer, A. J., T. Ayers, J. Grass, M. Lynch, F. J. Angulo, and B. E. Mahon. 2012. Nonpasteurized dairy products, disease outbreaks, and state laws-United States, 1993-2006. Emerg. Infect. Dis. 18:385-391.

Mungai, E. A., C. B. Behravesh, and L. H. Gould. 2015. Increased outbreaks associated with nonpasteurized milk, United States, 2007-2012. Emerg. Infect. Dis. 21:119-122. https://doi.org/10 $.3201 /$ eid2101.140447.

NORS (National Outbreak Reporting System). 2018. National Outbreak Reporting System. Accessed Mar. 1, 2018. https://www.cdc .gov/nors/index.html.

Oliver, S. P., B. M. Jayarao, and R. A. Almeida. 2005. Foodborne pathogens in milk and the dairy farm environment: Food safety and public health implications. Foodborne Pathog. Dis. 2:115-129 https://doi.org/10.1089/fpd.2005.2.115.

Pennsylvania Statutes. 1982. Title 31 P.S. Food $\S 646$. Permit; application; reimbursement of inspection expenses; reciprocal agreements. Accessed Mar. 1, 2018. https://codes.findlaw.com/pa/title-31-ps -food/pa-st-sect-31-646.html.

Pennsylvania Statutes. 1961. Title 31 P.S. Food $\S 652$. Raw milk; handling. Accessed Mar. 1, 2018. https://codes.findlaw.com/pa/title -31-ps-food/pa-st-sect-31-652.html. 